\title{
Knowledge Growth and the Allocation of Time*
}

\author{
Robert E. Lucas, Jr. Benjamin Moll \\ University of Chicago Princeton University
}

February 15, 2011

\begin{abstract}
We analyze a model economy with many agents, each with a different productivity level. Agents divide their time between two activities: producing goods with the production-related knowledge they already have, and interacting with others in search of new, productivity-increasing ideas. Each meeting involves two people, each with a different productivity level. Both parties emerge from a meeting with the higher of the two productivities. These choices jointly determine the economy's current production level and its rate of learning and real growth. The state of the economy is completely described by the distribution of productivity levels.

Individuals' time allocation decisions depend on the distribution because the productivity levels of others determine their own chances of improving their productivities through search. The time allocations of everyone in the economy in turn determine the evolution of its productivity distribution. We construct the balanced growth path for this economy, thereby obtaining a theory of endogenous growth that captures in a tractable way the social nature of knowledge creation. We report numerical experiments that describe how the level and rate of growth of productivity along the balanced growth path vary with changes in taxes and other parameters.
\end{abstract}

*We thank Paco Buera for helpful comments. 